\title{
ORIGINAL INVESTIGATIONS \\ Infusion of Five Percent Dextrose Increases Mortality and Morbidity Following Six Minutes of Cardiac Arrest in Resuscitated Dogs
}

\author{
Edward F. Lundy, John E. Kuhn, Jennifer M. Kwon, Gerald B. Zelenock, and Louis G. D'Alecy
}

\begin{abstract}
The aim of this study was to assess the effect of dextrose administration during and following cardiac resuscitation on mortality and morbidity. Thirty-one dogs anesthetized with halothane were subjected to six minutes of ventricular fibrillation and were resuscitated with open chest cardiac message. All dogs were successfully resuscitated. Thirteen received no dextrose infusion and were fully ambulatory, eating and drinking at 24 hours. Ten of the 18 dogs receiv-
\end{abstract}

GUDDEN CARDIAC ARREST is a leading $N$ cause of mortality in the United States, accounting for approximately 384,000 deaths per year. ${ }^{1}$ The standardization of cardiac life support protocols, the establishment of rapid response emergency medical systems, and the education and certification of both medical and lay personnel have reduced the mortality associated with sudden cardiac arrest; however, mortality rates in most areas are still approximately $85 \% .^{2} \mathrm{Car}-$ diac arrest protocols include the initial establishment of a venous access to facilitate drug administration. The patency of this access is maintained with a continuous infusion of fluids which routinely contain $5 \%$ dextrose. When an individual is found unconscious and no history is available, an ampule of $50 \%$ dextrose is frequently administered to correct for possible hypoglycemia. These uses of dextrose are generally considered either beneficial or at least innocuous. The treatment groups in this study were specifically designed to evaluate the use of dextrose in an experimental model mimicking the clinical setting of cardiac arrest.

From the Departments of Physiology and Surgery, the University of Michigan Medical School, Ann Arbor.

Supported in part by National Institute of Health Biomedical Research Support Grant No. SO7RR05383 and Short Term Training Grant No. 2T35NS07197-06, the University of Michigan Department of Surgery, and the American Heart Association of Michigan.

Address reprint requests to Louis G. D'Alecy, DMD, PhD, Department of Physiology, 7799 Medical Science Bldg II, University of Michigan, Ann Arbor, MI 48109.

(c) 1987 by Grune \& Stratton, Inc.

0883-9441/87/0201-0001\$05.00/0 ing an infusion of $5 \%$ dextrose died before 24 hours and the eight that survived were profoundly impaired. Significantly greater neurologic deficits were recorded for dogs with higher blood glucose concentrations. We conclude that the inclusion of dextrose in fluids used in resuscitation increases mortality and morbidity.

(c) 1987 by Grune \& Stratton, Inc.

Several experimental $\left.\right|^{3-8}$ and clinical ${ }^{9,10}$ studies have demonstrated that hyperglycemia prior to primary cerebral ischemic events will increase mortality and the severity of the associated neurologic deficit. The potential clinical importance of postresuscitation blood glucose levels was recently suggested in a retrospective study of resuscitated patients. ${ }^{11}$ Elevated blood glucose levels at the time of hospital admission were strongly correlated with an adverse neurologic outcome. However, the role of exogenous dextrose administration in elevating blood glucose levels and exacerbating ischemic damage was not evaluated by these investigators.

We recently demonstrated that $5 \%$ dextrose administered prior to cardiac arrest and resuscitation increases the anticipated mortality and neurologic deficit. ${ }^{12}$ However, in the vast majority of cardiac arrest cases, dextrose administration begins during, rather than prior to, the resuscitation effort. In this study we tested the hypothesis that even the routine administration of dextrose solutions begun at the initiation of the resuscitation effort impairs survival following resuscitation from cardiac arrest.

\section{MATERIALS AND METHODS}

\section{Animal Preparation and Experimental Procedure}

Thirty-one fed mongrel dogs (15.9 to $28.6 \mathrm{~kg}$ ) were premedicated with morphine sulfate, (1.5 mg/ $\mathrm{kg} \mathrm{IM}$ ). Anesthesia was induced with $5 \%$ halothane via mask and demand ventilation. Once anesthetized, the dogs were intubated and maintained on $1 \%$ to $2 \%$ halothane (Foregger, Compact-75) via controlled ventilation (Bennett, Anesthesia Ventilator; Puritan Bennett Corp, Westmont, IL). Neuromuscular 
blocking agents were not used. Carbon dioxide concentration in respiratory gas was continuously monitored (Beckman LB-2) with an infrared analyzer and end expiratory gas was maintained between $4 \%$ and $5 \%$. Prearrest arterial blood glucose and $\mathrm{pH}$ measurements were made, and blood $\mathrm{pH}$ was adjusted to 7.41 by sodium bicarbonate administration, and carbon dioxide tension was adjusted by manipulating ventilation. An esophageal temperature probe was inserted to the level of the heart. Body temperature was monitored and maintained at $39^{\circ} \mathrm{C}$ with a heating pad and proportional controller. $\mathrm{An}$ indwelling urethral catheter was placed to allow estimation of urine production. Two venous catheters were inserted: one through the external jugular vein to the superior vena cava for drug administration and central venous pressure monitoring and the other in the femoral vein for fluid infusion. $\Lambda$ catheter was placed in the femoral artery to monitor pulsatile blood pressure and for the withdrawal of arterial blood samples.

A left thoracotomy at the fifth intercostal space provided access to the heart, and the pericardium was opened to permit direct cardiac compression. Subcutaneous electrocardiographic electrodes were placed to monitor Lead II ECG. This ECG, along with mean and pulsatile arterial pressure, heart rate, and expiratory carbon dioxide tension were recorded on an oscillograph (Gould-Brush 200). When the preparation was complete, the dogs were disconnected from the anesthesia machine and connected to a room air ventilator (Harvard 607) to reduce and standardize the level of anesthesia at which fibrillation would be induced. The heart was fibrillated after corneal reflexes had consistently returned by delivering a $60-\mathrm{Hz}, 2-\mathrm{ms}$ square wave stimulus to the epicardial surface of the left ventrical. Circulatory arrest was confirmed by evaluation of the ECG tracing, arterial pressure pulse, and by direct observation.

After six minutes of circulatory arrest, resuscitation began following advanced cardiac life support protocols, which were modified for dogs. All dogs received an infusion of either lactated Ringers's $(\mathrm{n}=13)$ or $5 \%$ dextrose in lactated Ringer's $(n=18)$. The infusion fluid was administered at a calibrated rate (IVAC 530 ) of $120 \mathrm{~mL} / \mathrm{h}$ for the first six hours, and then at $65 \mathrm{~mL} / \mathrm{h}$ for the next 18 hours. $\Lambda$ subgroup of five of the $13 \mathrm{dogs}$ in the lactated Ringer's infusion group and five of the 18 in the $5 \%$ dextrose in lactated Ringer's infusion group received a bolus injection of $50 \%$ dextrose. All other dogs received a bolus injection of lactated Ringer's at the start of resuscitation. The volume of each bolus (11 to 21 $\mathrm{mL}$ of solution) was adjusted to the dog's body weight to give a volume corresponding to a dose of one $50-\mathrm{mL}$ ampule of $50 \%$ dextrose to a $70-\mathrm{kg}$ man. Total fluid volumes and total dextrose for each group is given in Table 1 .
The resuscitation effort began with direct cardiac massage, which maintained continuously monitored arterial blood pressure above $75 \mathrm{~mm} \mathrm{Hg}$. In all dogs drugs were rapidly injected into the central venous catheter in the following sequence and doses: the treatment fluid bolus; an epinephrine injection $(20 \mu \mathrm{g} / \mathrm{kg})$ and infusion $(4 \mu \mathrm{g} / \mathrm{kg} / \mathrm{min})$ (femoral venous catheter); an injection of $\mathrm{NaHCO}_{3}(2 \mathrm{mEq} /$ $\mathrm{kg})$; an injection of lidocaine $(1 \mathrm{mg} / \mathrm{kg})$; and an injection of $\mathrm{CaCl}_{2}(25 \mathrm{mg} / \mathrm{kg})$. As soon as this initial sequence of drugs was administered (approximately one minute) defibrillation was attempted by delivering a charge of 40 to $80 \mathrm{~J}$ (Lifepak-3 Physio-Control; Redmond, WA), with $31 \mathrm{~cm}^{2}$ paddles placed on the ventricular surface. Additional injections or charges were administered when indicated by arterial blood pressure and ECG tracings. Epinephrine infusion was adjusted to maintain mean arterial pressure between 100 and $125 \mathrm{~mm}$ $\mathrm{Hg}$, and was stopped when the dog was capable of maintaining a mean pressure greater than $100 \mathrm{~mm} \mathrm{Hg}$, or at six hours postarrest.

The chest was closed and evacuated when a stable rhythm and pressure developed. The dogs were ventilated until spontaneous ventilation ensued and were extubated upon the return of the gag reflex. The dogs were then placed in a cage where blood pressure, heart rate, ECG, and central venous pressure were continuously monitored for 24 hours using a standard dog jacket and swivel (Alicc King Chatham Mcdical Arts). An antibiotic (Polyflex, $6.6 \mathrm{mg} / \mathrm{kg} \mathrm{IM}$ ) was given to all dogs, and morphine sulfate $(1.5 \mathrm{mg} / \mathrm{kg} \mathrm{IM})$ was used as needed when the dogs showed signs of pain or discomfort.

At one, two, six, and 24 hours postarrest, a neurologic score $^{12}$ described in Tablc 2 , was assigncd. All scoring was done by two or more investigators who referred to written descriptions of each test condition. Postmortem examinations of the heart, lungs, and wound site were conducted to verify catheter placements and to identify hemorrhage, heartworm infestation, or any iatrogcnic problem relating to the thoracotomy or resuscitation that may have contributed to the death of any of the dogs. The entire experimental procedure conformed to the guidelines set by the American Physiological Society and was approved by the University of Michigan Unit for Laboratory Animal Mcdicine Vertebrate Animal Use Committee (D001068D)

\section{Data Analysis}

Statistical analysis was performed with the aid of the Michigan Interactive Data Analysis System (MIDAS) on an Amdahl 5860 computer. Comparison of model parameters were assessed with Student's $t$-test. Both the Student's $t$-test and nonparametric Kurskel-Wallis tests were used to evalu-

Table 1. Treatment Groups

\begin{tabular}{ccccc}
\hline Group & $\mathrm{n}$ & Bolus & $\begin{array}{c}\text { Total Volume } \\
(\mathrm{mL})\end{array}$ & $\begin{array}{c}\text { Total Dextrose } \\
(\mathrm{g} / \mathrm{kg} / 24 \mathrm{~h})\end{array}$ \\
\hline \multirow{2}{*}{ LR infusion $(\mathrm{n}=13)$} & 8 & LR & 1,911 & None \\
D5LR infusion $(\mathrm{n}=18)$ & 5 & D50 & 1,911 & 0.36 \\
& 13 & LR & 1,911 & 4.74 \\
\hline
\end{tabular}

Dogs were randomly assigned to either dextrose containing (D5LR) or dextrose free (LR) infusion groups. Each infusion group contained a subgroup of five dogs given an initial dextrose bolus, thus defining four treatments which varied only by total dextrose to be administered 
Table 2. Neurologic Deficit Score

\begin{tabular}{|c|c|}
\hline \multicolumn{2}{|l|}{ Consciousness } \\
\hline Normal & (0) \\
\hline Conscious continually & (3) \\
\hline Conscious intermittently & (6) \\
\hline Stuporous & $(12)$ \\
\hline Light Coma & $(15)$ \\
\hline Deep Coma & $(18)$ \\
\hline Subtotal & $-/ 18$ \\
\hline \multicolumn{2}{|l|}{ Motor function } \\
\hline Normal & (0) \\
\hline Minimal ataxia & (2) \\
\hline Ataxia & (4) \\
\hline Stands spontaneously & (6) \\
\hline Sits spontaneously & (10) \\
\hline Sits if posed & (12) \\
\hline Spontaneous dorsal recumbency & (14) \\
\hline Posed dorsal recumbency & (16) \\
\hline Spontaneous purposeful & (18) \\
\hline Provoked purposeful & $(20)$ \\
\hline Reflex, spastic, or convulsive movement only & (24) \\
\hline No movement & (28) \\
\hline Subtotal & 128 \\
\hline \multicolumn{2}{|l|}{ Respiration } \\
\hline Normal & (0) \\
\hline Extubated/abnormal & (6) \\
\hline Intubated/spontaneous & (12) \\
\hline On ventilator & (18) \\
\hline Subtotal & $/ 18$ \\
\hline \multicolumn{2}{|l|}{ Cranial Nerves } \\
\hline \multicolumn{2}{|l|}{ (strong $=0$, weak $=1$, absent $=2$ ) } \\
\hline Corneal reflex & (2) \\
\hline Pupillary light reflex & (2) \\
\hline Facial sensation & (2) \\
\hline Gag reflex & (2) \\
\hline Jaw reflex & (2) \\
\hline Olfactory reflex & (2) \\
\hline Swallowing reflex & (2) \\
\hline Subtotal & -116 \\
\hline \multicolumn{2}{|l|}{ Spinal Nerves } \\
\hline \multicolumn{2}{|l|}{$($ normal $=0$, spastic $=2$, flaccid $=4)$} \\
\hline Limb tone: front & (4) \\
\hline Limb tone: hind & (4) \\
\hline \multicolumn{2}{|l|}{ (normal $=0$, weak $=2$, absent $=4$ ) } \\
\hline Pain reflex: front & (4) \\
\hline Pain reflex: hind & (4) \\
\hline Knee jerk reflex & (4) \\
\hline Subtotal & -120 \\
\hline TOTAL $=$ & $-1 / 100$ \\
\hline
\end{tabular}

Neurologic deficit score (scaled 0-100) addresses five categories of tunction and increases with severity of damage.

ate neurologic scores. Fisher's exact test was used for survival data. All average data is expressed as mean \pm 1 SEM. The sample size (n) for all experiments is the number of animals. Exact $P$ values are given except when $P$ is greater than .05 where it is reported as nonsignificant (NS).

\section{RESULTS}

The average values of the two infusion treatment groups for the prearrest variables of opera- tive time (anesthesia induction to fibrillation), heart rate, arterial blood $\mathrm{pH}$, end-expiratory carbon dioxide, and arterial blood glucose were not found to be statistically different (Table 3 ). Body weight and mean arterial pressure were statistically higher in the group that was to be given $5 \%$ dextrose in lactate Ringer's despite random assignment of animals to treatment groups. The subgroups receiving the additional bolus injection of $50 \%$ dextrose were not found to be statistically different in the prearrest, resuscitation, or primary postarrest variables for cardiovascular and respiratory function, survival time and neurologic deficit scores but tended to have a lower blood $\mathrm{pH}$. The bolus subgroups were thus included in the two infusion treatment groups for subsequent analysis.

All 31 dogs were successfully resuscitated. Figure 1 illustrates the time of death for each dog and the survival rate for each group. All 13 dogs that received lactated Ringer's infusions were alive at 24 hours. Ten of $18 \mathrm{dogs}(56 \%)$ receiving dextrose infusion were dead at 24 hours, and as early as 11 hours postresuscitation 9 of these 10 dogs had died. Mortality was both early and excessive in dogs receiving the dextrose infusion.

None of the dogs died from ventricular fibrillation and all dogs had regained spontaneous ventilation with hyperpnea within less than two hours. All the animals that died had fixed and dilated pupils, little or no somatosensory

Table 3. Prearrest Variables

\begin{tabular}{|c|c|c|c|}
\hline Variable & $\begin{array}{c}\text { LR Infusion } \\
\text { With Dextrose } \\
\text { (Sample Size, 18) }\end{array}$ & $\begin{array}{l}\text { LR Infusion } \\
\text { Without Dextrose } \\
\text { (Sample Size, 13) }\end{array}$ & $P$ \\
\hline Body weight (kg) & $21.0 \pm 0.7$ & $18.8 \pm 0.7$ & .04 \\
\hline $\begin{array}{l}\text { Operative time } \\
\text { (min) }\end{array}$ & $94 \pm 5$ & $98 \pm 9$ & NS \\
\hline $\begin{array}{l}\text { Mean arterial pres- } \\
\text { sure (mm Hg) }\end{array}$ & $131 \pm 5$ & $115 \pm 4$ & .02 \\
\hline $\begin{array}{l}\text { Heart rate (beats/ } \\
\text { min) }\end{array}$ & $101 \pm 6^{*}$ & $112 \pm 13$ & NS \\
\hline $\begin{array}{l}\text { Arterial blood } \mathrm{pH} \\
\text { (U) }\end{array}$ & $7.38 \pm .02 \dagger$ & $7.37 \pm .02 \S$ & NS \\
\hline $\begin{array}{l}\text { End-expired } \mathrm{CO}_{2} \\
\qquad(\%)\end{array}$ & $3.9 \pm 0.2$ & $3.9 \pm 0.2$ & NS \\
\hline $\begin{array}{l}\text { Arterial blood glu- } \\
\text { cose }(\mathrm{mg} / \mathrm{dL})\end{array}$ & $143 \pm 6 \ddagger$ & $140 \pm 9$ & NS \\
\hline
\end{tabular}

Average prearrest values of the two infusion groups (mean \pm 1 SEM, $P$ values, Student's $t$ analysis).

*Value was obtained with a smaller sample size, 17. †Value was obtained with a smaller sample size, 8. $\ddagger$ Value was obtained with a smaller sample size, 9 . §Value was obtained with a smaller sample size, 12. 


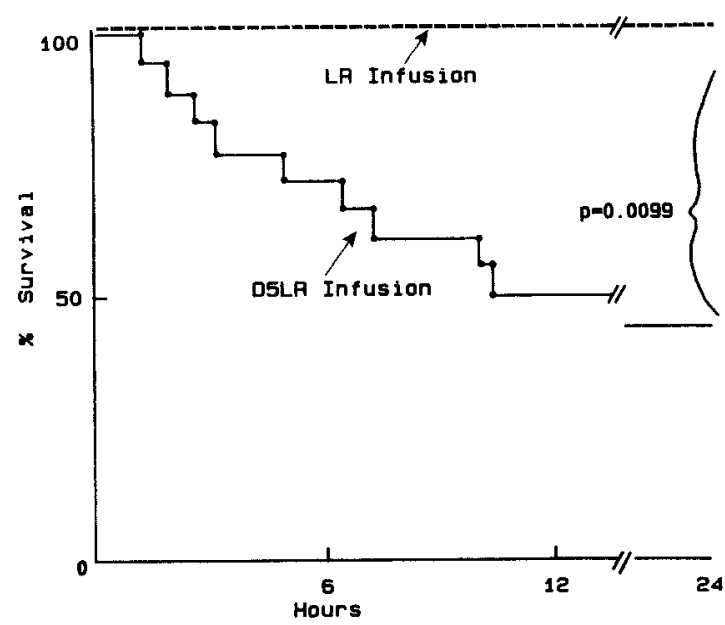

Fig 1. Percent survival for the group receiving the LR infusion $(n=13)$ (without dextrose) and the group receiving $5 \%$ dextrose in LR $(\mathbf{n}=18$ ). Fisher's exact test was used to compute the $P$ value at $24 \mathrm{hrs}$. All dogs receiving LR infusion were alive at 24 hours.

response, and death was often preceded by convulsivelike activity, limb extension with arching of the back. Cardiopulmonary depresssion appeared secondary to progressive neurologic damage. Subsequent postmortem examination failed to reveal any iatrogenic problems related to the thoracotomy or resuscitation that could account for the death of any animal.

There was no statistical difference detected in prearrest blood glucose concentrations (Table 3). Both groups had increased postarrest blood glucose levels (Table 4); however the dogs receiving the dextrose infusion had significantly higher postresuscitation glucose levels. The exogenously administered dextrose presumably added to that mobilized by the animal in response to stress.
The time from the beginning of resuscitation to the establishment of stable cardiac rhythm and a mean arterial blood pressure greater than $75 \mathrm{~mm} \mathrm{Hg}$ without external compression (resuscitation time) was not statistically different between groups (Table 5). Also, no difference was detected between the number of defibrillating shocks, amount of lidocaine, $\mathrm{NaHCO}_{3}$, or morphine used. The time the animals required ventilatory assistance was not different at a $P=$ .05 level despite an almost doubling of ventilation time in the group of dogs that received the dextrose infusion. There was no detectable difference in the interval from arrest until the animals could be extubated; however, all animals receiving an infusion of lactated Ringer's were extubated by three hours. In contrast, four of the 18 dogs receiving D5LR infusion died while still intubated.

$\Lambda$ marked difference in epinephrine requirements was observed for the dextrose infusion group (Table 5). This group required, on the average, approximately three times more $(P=.05)$ epinephrine administered as injections than the lactated Ringer's infusion group. Also, the length of time the dextrose infusion animals required an epinephrine infusion to maintain 100 to $125 \mathrm{~mm} \mathrm{Hg}$ mean arterial blood pressure was almost twice as long as that of the group without dextrose, but this difference did not reach statistical significance. (The time of infusion is reported because the epinephrine infusion rate was continually titrated to maintain a mean arterial pressure of 100 to $125 \mathrm{~mm} \mathrm{Hg}$ ). At six hours, the only animals requiring epinephrine infusion were in the dextrose infusion group (all

Table 4. Postresuscitation Physiologic Measurements

\begin{tabular}{|c|c|c|c|c|c|}
\hline Variable & $n$ & $\begin{array}{c}\text { LR Infusion } \\
\text { With Dextrose } \\
\text { (Sample Size, 18) }\end{array}$ & $n$ & $\begin{array}{l}\text { LR Infusion } \\
\text { Without Dextrose } \\
\text { (Sample Size, 13) }\end{array}$ & $P$ \\
\hline Heart rate $6 \mathrm{~h}$ (beats $/ \mathrm{min}$ ) & 11 & $168 \pm 11$ & 13 & $146 \pm 11$ & NS \\
\hline Heart rate 24 h (beats $/ \mathrm{min}$ ) & 8 & $120 \pm 13$ & 13 & $143 \pm 11$ & .002 \\
\hline Arterial blood glucose $1 \mathrm{~h}$ & & & & & \\
\hline$(\mathrm{mg} / \mathrm{dL})$ & 9 & $408 \pm 59$ & 12 & $256 \pm 16$ & .011 \\
\hline Arterial blood $\mathrm{pH} 1 \mathrm{~h}$ & 8 & $7.40 \pm .04$ & 11 & $7.44 \pm .03$ & NS \\
\hline $\begin{array}{l}\text { End-expired } \mathrm{CO}_{2} \text { on ventila- } \\
\text { tor }(\%)\end{array}$ & 16 & $4.2 \pm 0.2$ & 13 & $4.1 \pm 0.1$ & NS \\
\hline $\begin{array}{l}\text { End-cxpired } \mathrm{CO}_{2} \text { off ventila- } \\
\text { tor }(\%)\end{array}$ & 16 & $3.4 \pm 0.2$ & 13 & $3.1 \pm 0.2$ & NS \\
\hline $\begin{array}{l}\text { End expired } \mathrm{CO}_{2} \text { off vent } 20 \\
\text { min later }(\%)\end{array}$ & 13 & $2.9 \pm 0.2$ & 8 & $2.4 \pm 0.2$ & NS \\
\hline
\end{tabular}

Average postresuscitation values of the two infusion groups (mean \pm 1 SEM, $P$ values, Student's $t$ analysis). Two "off ventilator" end expiratory values are given: one as soon as value stabilized and the other 20 minutes after. 
Table 5. Resuscitation Procedure Variables

\begin{tabular}{|c|c|c|c|}
\hline Variable & $\begin{array}{c}\text { LR Infusion } \\
\text { With Dextrose } \\
\text { (Sample Size, 18) }\end{array}$ & $\begin{array}{c}\text { LR Infusion } \\
\text { Without Dextrose } \\
\text { (Sample Size, 13) }\end{array}$ & $P$ \\
\hline $\begin{array}{l}\text { Resuscitation time } \\
\text { (min) }\end{array}$ & $12.2 \pm 2.2$ & $7.1 \pm 0.9$ & NS \\
\hline No. of shocks & $5 \pm 1$ & $3 \pm 1$ & NS \\
\hline $\begin{array}{l}\text { Ventilation time } \\
\text { (min) }\end{array}$ & $44 \pm 13^{*}$ & $25 \pm 3$ & NS \\
\hline $\begin{array}{l}\text { Extubation time } \\
\text { (min) }\end{array}$ & $175 \pm 35 \dagger$ & $125 \pm 24$ & NS \\
\hline $\begin{array}{l}\text { Epi injection dose } \\
\text { (mg/kg) }\end{array}$ & $93.3 \pm 25.0$ & $30.8 \pm 6.0$ & .05 \\
\hline $\begin{array}{l}\text { Epi infusion time } \\
\text { (min) }\end{array}$ & $141 \pm 36$ & $71 \pm 16$ & NS \\
\hline $\begin{array}{l}\text { Total } \mathrm{NaHCO}_{3} \text { dose } \\
\quad(\mathrm{mEq} / \mathrm{kg})\end{array}$ & $3.8 \pm 0.2$ & $2.1 \pm 0.1$ & NS \\
\hline $\begin{array}{l}\text { Total lidocaine dose } \\
\qquad(\mathrm{mg} / \mathrm{kg})\end{array}$ & $6.4 \pm 1$ & $6.4 \pm 1$ & NS \\
\hline $\begin{array}{l}\text { Calcium chloride } \\
\text { (mg/kg) }\end{array}$ & $49 \pm 14$ & $31 \pm 3$ & NS \\
\hline $\begin{array}{l}\text { Morphine dose } \\
(\mathrm{mg} / \mathrm{kg})\end{array}$ & $1.3 \pm 0.5 \ddagger$ & $1.4 \pm 0.6$ & NS \\
\hline
\end{tabular}

Average values of the two infusion groups taken during the resuscitation procedure (mean \pm 1 SEM, $P$ values, Student's $t$ analysis).

*Value was obtained with a smaller sample size, 16. †Value was obtained with a smaller sample size, 13.

$\ddagger$ Value was obtained with a smaller sample size, 17.

having received a dextrose bolus) and the average infusion rate at this time for the four animals was $2.6 \mu \mathrm{g} / \mathrm{kg} / \mathrm{min}$, or more than half the initial infusion rate used to initiate resuscitation.

Figure 2 indicates the mean arterial pressure from the end of the six-hour support period to 24 hours, during which time no statistically significant differences in mean arterial pressure were detected. Heart rate at six hours was not statistically different but at 25 hours it was higher in the group without dextrose (Table 4). Urine was collected for the one to two hours prior to and, when possible, for six hours after the arrest. No more than $850 \mathrm{~mL}$ of urine was collected during this eight hours despite the infusion or injection of approximately $800 \mathrm{~mL}$ of fluid. Thus, there was no suggestion of a glucose induced diuresis, hypotension, or reflex tachycardia.

The total neurologic deficit score (Table 2) at one, two, six, and 24 hours is illustrated in Fig 3. As early as one hour postarrest the dextrose infusion group had a significantly greater neurologic deficit score than the lactated Ringer's group (Student's $t$ ). This separation is retained at two, six, and 24 hours. If dead animals (score of 100) are excluded from such analysis (Fig 4),

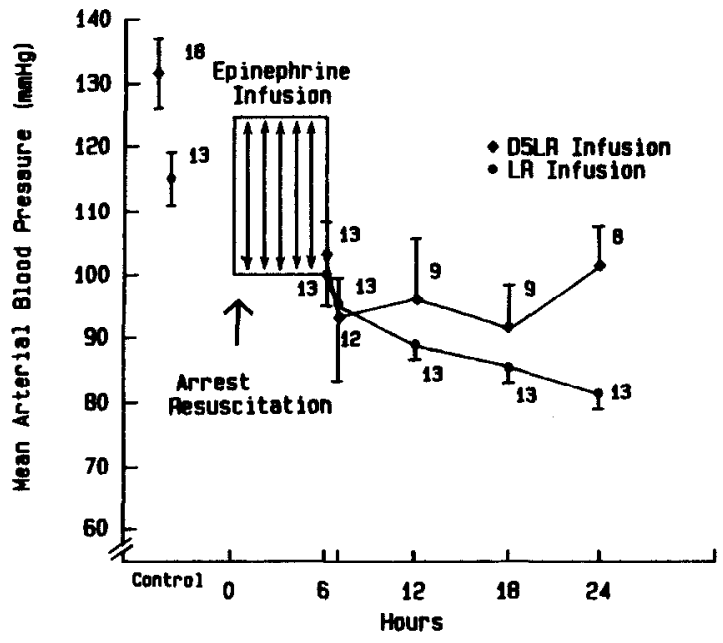

Fig 2. The bar at the far left indicates 1 SEM about the prearrest value of mean arterial pressure for each group. The box with arrows indicates the range in which pressure was controlled for the six hours following arrest and resuscitation. Sample size is next to data points. Values were taken just after six hours when pressure stabilized and at $7,12,18$, and 24 hours postresuscitation.

the sample size in the dextrose infusion group is reduced to 13 ( 5 of 18 dead) by six hours and to 8 ( 10 of 18 dead) by 24 hours reducing the statistical separation of thesc groups. This analysis clearly biases the data in favor of the dextrose group in that the dextrose group thus contains only the least impaired dogs while the no dextrose group retains all animals. Despite the bias

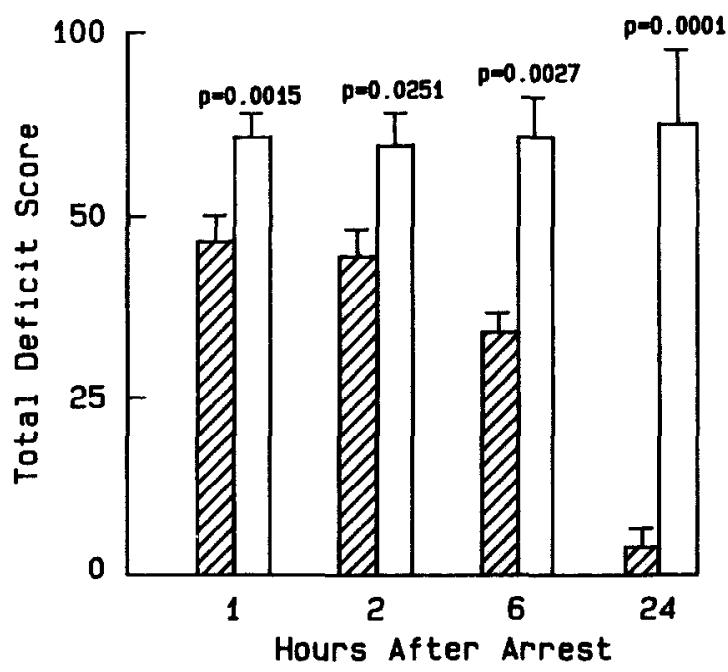

Fig 3. Postresuscitation neurologic deficit. Values are the total neurologic score for all dogs (including dead dogs as a maximum deficit of 100 ) (mean \pm 1 SEM, $P$ values for Student's $t$ analysis). LR infusion ( $n=13$ ): $\square$ D5LR infusion $(n-18)$. 


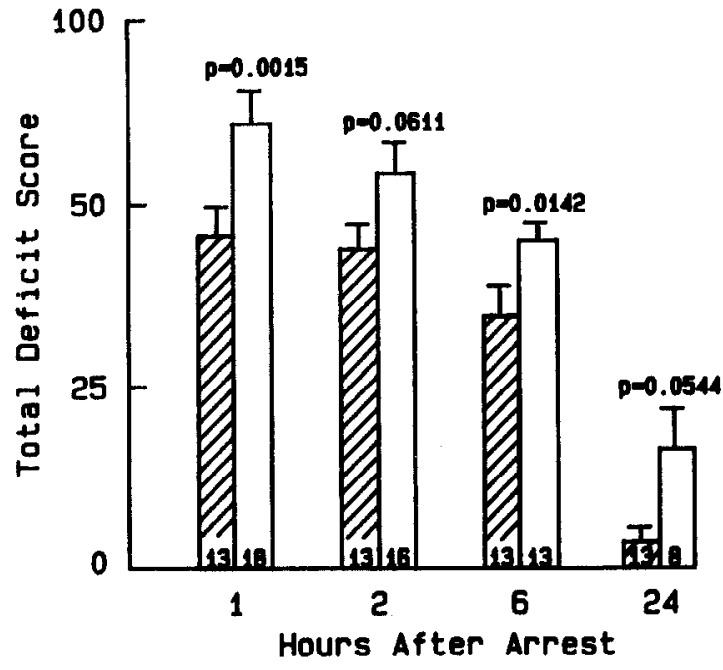

Fig 4. Postresuscitation neurologic deficit. Values are the total neurologic score for only the dogs which remained alive (mean \pm 1 SEM, $P$ values for Student's $t$ analysis). Note the group receiving the LR infusion is identical in Figs 3 and 4. $D$ LR infusion; $\square$ D5LR infusion.

introduced by this form of analysis the greater neurologic deficit in the group receiving dextrose is still apparent.

In each group the motor component of the neurologic score contributed strongly to the total deficit (Fig 5). The respiratory, spinal nerve, and cranial nerve indices of neurologic deficit were less discriminating. They often failed to show deficits at 24 hours, and the spinal and cranial nerve performance was often near normal within the first six hours postarrest. When the motor deficit score was plotted relative to change in blood glucose concentration (postresuscitation/ prearrest), a neurologic deficit threshold was apparent as blood glucose values increased twofold (Fig 6).

\section{DISCUSSION}

The idea that glucose is damaging during cerebral ischemic events is not entirely new, but it is substantially underappreciated in both experimental protocols and daily clinical practice. Several studies have been published indicating that hyperglycemia prior to a focal or global cerebral insult increases neurologic damage..$^{5-10}$ These studies have clinical relevance in many commonly occurring clinical events, such as stroke, cardiac arrest, cardiopulmonary bypass, and carotid clamping. Unfortunately, these studies have, to date, had little impact on clinical

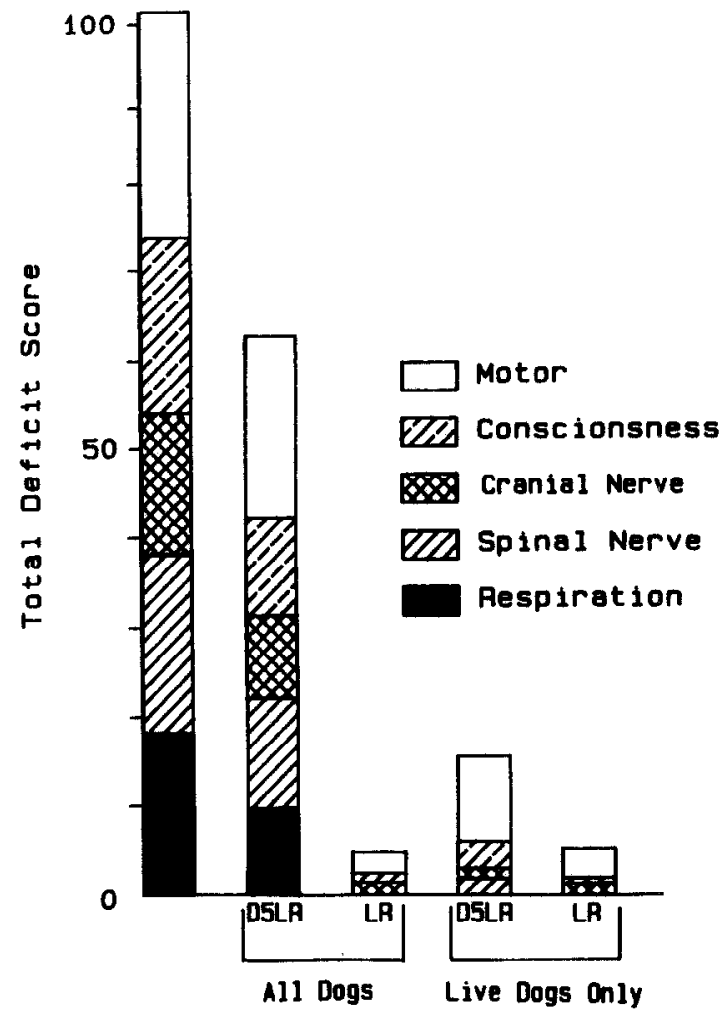

Fig 5. Components of total neurologic deficit at 24 hours. The key at the left indicates the maximum value obtainable for each component.

practice and, in particular, cardiopulmonary resuscitation protocols.

\section{Cardiac Arrest as a Model of Global Cerebral Ischemia}

Of the many models of global cerebral ischemia, the induction of cardiac arrest is potentially

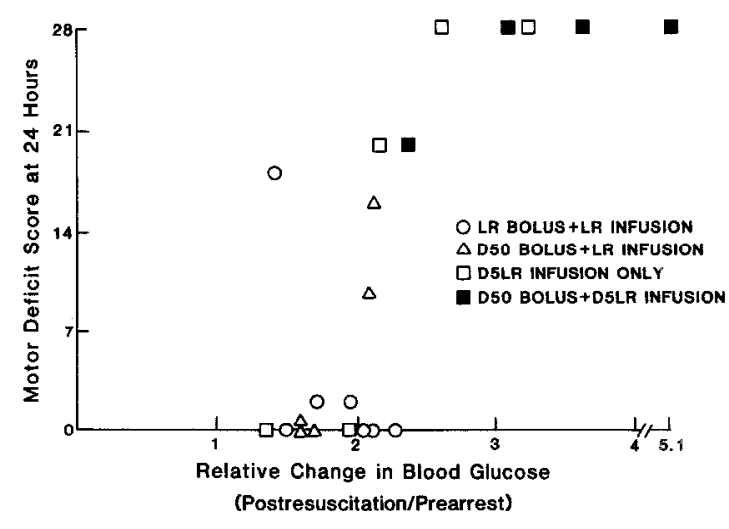

Fig 6. Motor deficit following changes in blood glucose. The relative change in blood glucose is plotted on the horizontal axis as postresuscitation blood glucose concentration divided by the prearrest concentration. Doubling blood glucose is the threshold for increased motor deficit. 
the most directly relevant to the clinical setting. However, there have been some important criticisms of studies using such models. ${ }^{13}$ One major problem is the high failure rate associated with many closed chest, external compression resuscitation attempts in dogs. In one such study involving 12 minutes of cardiac arrest, only 13 of 34 dogs were successfully resuscitated. ${ }^{14}$ Such low resuscitation rates raise concerns about the unusual tolerance of the small subgroup of surviving animals. The reasons for low resuscitation rates are rarely defined, but this failure to resuscitate is certainly due, in part, to variable and inadequate cerebral blood flow associated with closed chest compressions ${ }^{15}$ which may lengthen the effective period of ischemia. These concerns make comparisons of data within and between such studies difficult at best.

To obviate these problems, we chose to use open chest, direct cardiac compression to maintain a mean arterial pressure greater than $75 \mathrm{~mm}$ $\mathrm{Hg}$ and to hold our circulatory arrest time to a controlled six minutes. Resuscitation attempts that use direct cardiac compression result in improved cerebral blood flow, ${ }^{16,17}$ better maintenance of brain electrical activity, ${ }^{18}$ and improved brain recovery. ${ }^{19,20}$ Of the last 86 dogs fibrillated for this and two other studies, ${ }^{12,21}$ we resuscitated 85 , a failure rate of approximately $1.2 \%$. These results suggest that more reliable and consistent data can be obtained in canine models of cardiac arrest and resuscitation when direct cardiac compression is used as an alternative to closed chest compression. It is important to note that we are not necessarily advocating direct cardiac compression as the preferrcd technique in the clinical setting because this approach has not been fully evaluated in a controlled study.

Previous studies have reported that in canine and feline models, arrest times from 12 to 16 minutes were required to consistently produce detectable neurologic deficits. ${ }^{14,22-26}$ This is in contrast to humans who often develop neurologic damage after as little as four to six minutes of global cerebral ischemia. ${ }^{15,27}$ This apparent discrepancy has caused the questioning of the clinical relevance of previous cardiac arrest studies. Many causes can be suggested for the relatively long arrest times required to produce damage in animal studies, such as cortical mass differences, cooling effects in the laboratory setting, and species differences. Our data indicate that the reported differences may, in part, be due to the detrimental effects of dextrose. Dextrose is frequently administered to humans in a clinical setting, but it is not consistently used in a laboratory setting. We elected to begin resuscitation after only six minutes of cardiac arrest to more closely mimic clinically relevant arrest/resuscitation times and to use dextrose-containing intravenous fluids as they are uscd clinically.

Another potential criticism of using cardiac arrest and resuscitation as a model of global cerebral ischemia is the concern over the use of multiple drugs and their interactions with each other and anesthetics. Although we could not completely eliminate this influence, we did reduce and control its impact. The drugs used during the resuscitation effort were the minimum doses and types required to maintain blood pressure and cardiac function. We chose halothane as our general anesthetic because it permits rapid induction and recovery and it has not been reported to have protective effects following cerebral ischemia, as reported for example in the use of barbiturate anesthesia. ${ }^{28}$ The level of anesthesia for each animal was reduced and standardized by inducing arrest after the corneal lid reflex had consistently returned.

Ventilatory and blood pressure support was restricted to six hours and the level of support provided was recorded as an experimental variable. We chose to stop support at six hours to minimize and standardize the support given each animal. The fact that dogs receiving dextrose infusion required more pharmocologic support is interpreted as a detrimental effect of dextrose infusion. One might argue that continued blood pressure support would have "saved" the dogs that died after six hours. This might be true but would not change the conclusion that dogs given dextrose during resuscitation have greater morbidity and higher mortality than those given an infusion free of dextrose. Continuing intensive cardiorespiratory support for the full six hours favored the survival of the dextrose infusion group. Despite this more intensive support, the dextrose infusion group had the greater mortality.

As with any protocol involving neurologic 
evaluations, complete objectivity is difficult to obtain. The neurologic evaluation used in this study is our modification ${ }^{12}$ of a neurologic assessment developed by Nemoto et $\mathrm{al}^{23}$ and used by others in similar protocols. ${ }^{24}$ In order to minimize potential bias, at least two investigators performed every neurologic examination. For any result which was unclear, written descriptions of the various conditions were consulted and the examination was repeated until a score was agrecd upon. Table 2 gives the contribution of each scored deficit.

In this study the motor deficit component contributed most to the overall neurologic deficit score (Fig 5), perhaps due to the greater vulnerability of these functions compared to those controlled by the brain stem or spinal cord. ${ }^{3}$ Our functional assessments are consistent with histologic studies of brain tissue following arrest and resuscitation. These studies characteristically show damage in the cortex, basal ganglia, and cerebellum with relative sparing of the brain stem. ${ }^{3,29-37}$ Although morphine was used to alleviate postoperative pain, no animal required morphine for more than 12 hours postarrest, and there was no difference detected between groups in the amount of morphine used. This permitted the 24-hour neurologic deficit score to be relatively free from the influence of anesthesia, analgesia, or sedation.

Potential concern might arise regarding assigning a neurologic deficit score of 100 points to a dead dog. This could be misleading if the cause of death were ventricular fibrillation, hemorrhage, or any other noncerebral cause. Nlthough we cannot absolutely exclude the possibility that the deaths were unrelated to the neurologic impairment, the pattern of death for the ten dogs (10 of 31 tested) that died in this study before 24 hours was clearly suggestive of a primary cerebral event. Maximum deficit in cranial and spinal nerves was recorded prior to progessive depression of cardiopulmonary function. The typical pattern was one of fixed and dilated pupils with limb extension and arching of the back suggestive of brain swelling. This pattern and the absence of any evidence of primary cardiopulmonary failure justify the inclusion of dead dogs (scored as a maximum neurologic deficit of 100) in the analysis of data as shown in
Fig 3. Figure 4 shows the neurologic deficit data including only live dogs. Regardless of the type of statistical analysis the conclusion remains the same.

\section{Glucose and Ischemic Damage}

Since most cardiac arrests occur out of the hospital, prior administration of dextrose and the potential for a damaging role of elevated blood glucose in the outcome of resuscitated patients has not been a major clinical concern. Furthermore, Pulsinelli ${ }^{7}$ has reported that the postreperfusion administration of glucose in a four-vessel occlusion model of cerebral ischemia in the rat had no obvious neurologic consequences. However, a recent study by Longstreth and Inui ${ }^{11}$ reported that postresuscitation blood glucose levels taken at hospital admission were strongly correlated with neurologic outcome. They reported that patients who did not awaken after resuscitation had a mean blood glucose level of $341 \mathrm{mg} / \mathrm{dL}$, a value not uncommon in a clinical setting. The admitting blood glucose concentration of those that awoke $(262 \mathrm{mg} / \mathrm{dL})$ and the subgroup that was without neurologic deficit $(251 \mathrm{mg} / \mathrm{dL})$ was significantly lower. They did not speculate on the possibility that dextrose administration may have contributed to the greater neurologic damage they observed in patients with higher blood glucose. Our study specifically focused on the evaluation of dextrose administration begun after the insult of cardiac arrest to mimic a typical out-of-hospital arrest and resuscitation sequence. Administration of intravenous dextrose-containing fluids would contribute to the clcvation of blood glucose which, particularly in low flow states, could increase glycolytic flux and potentially increase neurologic deficit.

In a previous study ${ }^{12}$ we confirmed the observations of Pulsinelli et $\mathrm{al}^{7}$ and Meyers and Yamaguchi ${ }^{3}$ that pretreatment with glucose was detrimental. The current results indicate that dextrose administered after, as well as before, the initiation of cerebral ischemia can be damaging. Pulsinelli's ${ }^{7}$ observation that postreperfusion administration of glucose is of no consequence is perhaps due to species differences, or possibly differences in the model, ie, partial cerebral ischemia may occur in the four vessel occlusion 
model whereas total ischemia is assured during cardiac arrest. The duration and severity of the ischemic period, the rate at which reperfusion occurs and the existence and duration of reactive hyperemia or persistent low flow states may also contribute to differences in the response of these models of cerebral ischemia. Another possible explanation is the different method used for dextrose administration. Pulsinelli gave rats an intraperitoneal injection of D-glucose after reperfusion, whereas we tested intravenous administration of both a bolus and a continuous 24-hour infusion of dextrose. The dextrose bolus alone was minimally damaging and the 24 hour dextrose infusion was found to be damaging with or without the bolus of dextrose.

Dextrose administration in the setting of experimental cardiac arrest and resuscitation is associated with greater neurologic deficit and mortality. In an attempt to refine this relationship, blood glucose levels and neurologic deficit were plotted using the postresuscitation blood glucose values and the motor deficit score. No strong correlation was found with the absolute values of blood glucose. However, when we plotted the relative change in blood glucose against motor deficit, we noted a threshold for damage at the point where blood glucose is increased approximately twofold (Fig 6). Others ${ }^{38-40}$ have reported a threshold effect when evaluating the role of tissue lactate in ischemic brain damage.

During normal blood flow and oxygen tension, brain tissue lactate has been reported to be approximately $1.5 \mathrm{mmol} / \mathrm{L} / \mathrm{kg} .{ }^{41}$ This steadystate concentration could be maintained by a small, yet constant glycolytic metabolism and a constant flow of blood to remove lactate. Should blood flow (and hence $\mathrm{O}_{2}$ and glucose delivery change), it is conceivable that the balance between production and removal of lactate shifts such that tissue lactate increases. Cerebral blood flow 15 to 30 minutes after resuscitation following total global ischemia has been reported to be less than $20 \%$ of the original value..$^{25,42-48}$ This hypoperfusion phenomenon can last more than 18 hours postresuscitation. ${ }^{46}$ Meyers $^{38}$ and oth$\mathrm{ers}^{39,40}$ have shown a threshold for damage exists when tissue lactate exceeds 16 to $20 \mathrm{mmol} / \mathrm{L} / \mathrm{kg}$. Presumably, this threshold can be reached when a marked reduction in cerebral blood flow is combined with an increase in blood glucose, a situation that will drive glycolytic flux and result in the production and accumulation of tissue lactate. Interestingly, Pulsinelli et al have shown in the four-vessel occlusion model of global cerebral ischemia and reperfusion in the rat, ${ }^{7}$ that with an increase in blood glucose slightly more than twofold, histologic damage was detected in areas of the brain where blood flow was reduced to $15 \%$, but no damage was detected where blood flow was reduced to $25 \%$. Our analysis of a rather abrupt transition, or threshold, for cerebral damage is consistent with this regional blood flow analysis. We, however, draw attention to metabolic substrate delivery as a determining factor and not blood flow changes alone. In a state of prolonged ischemia, the addition of supplemental glucose to the blood, through an intravenous infusion, would increase tissue lactate production and accumulation, which could cause progressive tissue damage. In a recent study from our laboratory, ${ }^{49}$ 2-deoxyglucose was used to inhibit glycolytic metabolism in the setting of hyperglycemia-aggravated ischemic damage. In the Wistar rat, severe forebrain ischemia, but no mortality, is produced by permanent occlusion of the vertebral artcrics and 20 minutes of occlusion of the carotid arteries. The addition of $3 \mathrm{~g} / \mathrm{kg}$ glucose to the four-vessel occlusion model of cerebral ischemia produced $100 \%$ mortality in 24 hours; however, the further addition of $1.6 \mathrm{~g} / \mathrm{kg}$ 2 -deoxyglucose reduced the mortality to $40 \%$ and reduced morbidity. We concluded that augmented ischemic damage during hyperglycemia is a consequence of glycolytic flux because 2deoxyglucose, which decreases glucose uptake and glycolytic flux, decreased mortality and morbidity. The infusion of $5 \%$ dextrose in the present study parallels the hyperglycemia in the rat study; however, it remains speculative whether a comparable inhibition of glycolytic metabolism would eliminate the augmented damage we observed in resuscitated dogs. Thus, we can only hypothesize that the mechanism of augmented damage is through glycolytic metabolism to lactate. Hyperglycemia alone does not cause the damage, and the mechanisms of ischemic damage are manifold and beyond the scope of this study.

Although the heart metabolizes lactate more readily than the brain, lactate accumulation in the myocardium is ultimately associated with 
depressed pump function. ${ }^{50}$ If hyperglycemia exacerbates myocardial lactate accumulation, then an additional component of the epinephrine dependency may have been the need for inotropic support of a failing heart. Thus, although we believe the brain is the primary site of hyperglycemia-aggravated ischemic damage, we cannot exclude - and in fact would hypothesize-myocardial, renal, or other tissue damage as contributors to overall morbidity and mortality.

This study utilized a standardized and highly reproducible model of cardiac arrest and resuscitation. The only experimental variable was the administration of clinically relevant doses of dextrose as an intravenous drip and/or bolus. While no specific mechanism was evaluated, this descriptive study indicates that dextrose administration during and after resuscitation from cardiac arrest is associated with a greatly increased mortality and neurologic morbidity. Further, while all dogs were successfully resuscitated, those receiving dextrose infusions required substantially greater cardiorespiratory support in the postarrest period. These data suggest that in the halothane-anesthetized dog postarrest administration of dextrose may elevate the blood glucose concentration enough to increase mortality and morbidity. With the accumulation of evidence supporting the injurious role of elevated blood glucose concentration during ischemic events, we propose that dextrose-containing intravenous fluids may impair recovery from cardiac arrest and thus should be avoided in this setting.

\section{ACKNOWLEDGMENT}

We thank Physio-Control (Redmond, WA) for the generous gift of the Lifepak-3 defibrillator/monitor. We thank Puritan Bennett Corporation, (Westmont, IL) for the generous gift of a Compact-75 Anesthesia Machine and a Bennett BA-4 Anesthesia Ventilator. The Seralyzer Reflectance Photometer was a generous gift from the Ames Division of Miles Laboratories, Inc, and the heparin was graciously supplied by the Upjohn Company (Kalamazoo, MI). We would like to thank Mary Harper for her editorial assistance, Tamara Ball for assistance with data analysis, and Anita Burck and Kathy Simpson for their assistance with the illustrations.

\section{REFERENCES}

1. McIntyre KM, Lewis AJ, Winslow EBJ, et al: Sudden cardiac death, in McIntyre KM, Lewis AJ (eds): Textbook of Advanced Cardiac Life Support, Dallas, American Heart Association Office of Communications, 1981

2. Longstreth WT, Inui TS, Cobb LA, et al: Neurologic recovery after out-of-hospital cardiac arrest. Ann Intern Med 98:588-592, 1983

3. Myers RE, Yamaguchi S: Nervous system effect of cardiac arrest in monkeys. Arch Neurol 34:65-74, 1977

4. Siemkowicz E, Hansen AJ: Clinical restitution following cerebral ischemia in hypo-, normo- and hyperglycemic rats. Acta Neurol Scand 58:1-8, 1978

5. Ginsberg MD, Welsh FA, Rieder W, et al: Deleterious effect of glucose pretreatment on recovery from diffuse cerebral ischemia in cat. Part I. Local cerebral blood flow and glucose utilization. Stroke 11:347-354, 1980

6. Welch FA, Ginsberg MD, Rieder W, et al: Deleterious effect of glucose pretreatment on recovery from diffuse cerebral ischemia in the Cat. Part II. Regional metabolite levels. Stroke 11:355-363, 1980

7. Pulsinelli WA, Waldman S, Rawlinson D, et al: Moderate hyperglycemia augments ischemic brain damage: A neuropathologic study in the rat. Neurology 32:1239-1246, 1982

8. Pulsinelli WA, Waldman S, Rawlinson D, et al: Hyperglycemia converts ischemic neuronal damage into brain infarction. Neurology 32:1239-1246, 1982

9. Pulsinelli WA, Levy DE, Sigsbee B, et al: Increased damage after ischemic stroke in patients with hyperglycemia with or without established diabetes mellitus. Am J Med $74: 540-544,1983$
10. Candelise L, Landi G, Orazio EN, et al: Prognostic significance of hyperglycemia in acute stroke. Arch Neurol 42:661-663, 1985

11. Longstreth WT, Inui TS: High blood glucose level on hospital admission and poor neurological recovery after cardiac arrest. Ann Neurol 15:59-63, 1984

12. D'Alecy LG, Lundy EF, Barton KJ, et al: Dextrose containing intravenous fluid impairs outcome and increases death after 8 minutes of cardiac arrest and resuscitation in dogs. Surgery 100:505-511, 1986

13. Kirsch JR, Dean JM, Rogers MC: Current concepts in brain resuscitation. Arch Intern Med (in press)

14. Safar P, Stezoski W, Nemoto EM: Amelioration of brain damage after 12 minutes cardiac arrest in dogs. Arch Neurol 33:91-95, 1976

15. Safar P: Resuscitation after brain ischemia, in Grenvic $A$, Safar P, (eds): Brain Failure and Resuscitation. New York, Churchill Livingstone, 1981, p 156

16. Stajduhar K, Safar P, Steinberg R, et al: Cerebral blood flow (CBF) and other benefits from wider use of open-chest cardiopulmonary resuscitation. Crit Care Med 11:226, 1983 (abstr)

17. Arai T, Dote K, Tsukahara I, et al: Cerebral blood flow during conventional, new and open-chest cardiopulmonary resuscitation in dogs. Resuscitation 12:147-154, 1984

18. Yashon D, Wagner FC, Massopust LC, et al: Electrocorticographic limits of cerebral ability during cardiac arrest and resuscitation. Am J Surg 121:728-731, 1971

19. Alifimoff JK, Safar P, Bircher N, et al: Cerebral recovery after prolonged closed-chest, MAST-augmented, 
and open-chest cardiopulmonary resuscitation (CPR). Anesthesiology 53:S147, 1980 (suppl)

20. Bircher N, Safar P: Cerebral preservation during cardiopulmonary resuscitation. Crit Care Med 13:185-190, 1985

21. Kuhn JA, Steimle CN, Zelenock GB, et al: Ibuprofen improves survival and neurologic outcome after resuscitation from cardiac arrest. Resuscitation (in press)

22. Todd MM, Dunlop BJ, Shapiro HM, et al: Ventricular fibrillation in the cat: A model for global cerebral ischemia. Stroke 12:808-815, 1981

23. Nemoto EM, Bleyaert AL, Stezoski SW, et al: Global brain ischemia: A reproducible monkey model. Stroke 8:558564,1977

24. Todd MM, Chadwick MD, Shapiro HM, et al: The neurologic effects of thiopental therapy following experimental cardiac arrest in cats. Anesthesiology 57:76-86, 1982

25. Winegar $\mathrm{CP}$, Henderson $\mathrm{O}$, White $\mathrm{BC}$, et al: Early amelioration of neurologic deficit by lidoflazine after fifteen minutes of cardiopulmonary arrest in dogs. Ann Emerg Med 12:471-477, 1983

26. White BC, Winegar CP, Henderson O, et al: Prolonged hypoperfusion in the cerebral cortex following cardiac arrest and resuscitation in dogs. Ann Emerg Med 12:414417,1983

27. Cole S, Corday E: 4-Minute limit for cardiac resuscitation. JAMA 161:1454-1458, 1956

28. Smith AL, Hoff JT, Nielson SL: Barbiturate protection against cerebral infarction. Stroke 5:1-7, 1974

29. Pulsinelli WA, Brierley JB, Plum F: Temporal profile of neuronal damage in a model of transient forebrain ischemia. Ann Neurol 11:491-498, 1982

30. Weinberger LM, Gibbon MH, Gibbon JH Jr: Temporary arrest of circulation to the central nervous system: II. Pathologic effects. Arch Neurol Psychiatr 43:961-986, 1940

31. Grenell RG: Central nervous system resistance: $I$. The effects of temporary arrest of the cerebral circulation for periods of two to ten minutes. J Neuropathol Exp Neurol 5:131-154, 1946

32. Neuberger KT: Lesions of the human brain following circulatory arrest. J Neuropathol Exp Neurol 13:144-160, 1954

33. Richardson JC, Chambers RA, Heywood PM: Encephalopathies of anoxia and hypoglycemia. Arch Neurol 1:178-190, 1959

34. Mandel MM, Berry RG: Human brain changes in cardiac arrest. Surg Gynecol Obstet 108:692-696, 1959

35. Brierley JB: Anoxia-a neuropathological analysis of 18 cases, in Thieme G (ed): Proceedings of the Fourth
International Congress of Neuropathology, Munich, vol 3. Stuttgart, West Germany, 1969, pp 120-126

36. Steegmann AT: The neuropathology of cardiac arrest, in Minckler J, (ed): Pathology of the Nervous System. New York, McGraw-Hill, 1969, pp 1005-1029

37. Bell JA, Hodgson HJF: Coma after cardiac arrest. Brain 97:361-372, 1974

38. Myers RE: Lactic acid accumulation as a cause of brain edema and cerebral necrosis resulting from oxygen deprivation, in Korobkin R, Guilleminault C (eds): Advances in Perinatal Neurology. New York, Spectrum, 1979, pp $88-114$

39. Dienel GA, Pulsinelli WA, Duffy TE: Regional protein synthesis in rat brain following acute hemispheric ischemia. J Neurochem 35:1216-1226, 1980

40. Siesjo BK: Cell damage in the brain: A speculative synthesis. J Cereb Blood Flow Metab 1:155-185, 1981

41. Plum F: What causes infarction in ischemic brain?: The Robert Wartenberg lecture. Neurology 33:222-233, 1983

42. Ames A, Wright RL, Kowada M, et al: Cerebral ischemia. II. The no-reflow phenomenon. Am J Pathol 52:437-543, 1968

43. Cantu R, Ames A, DiGiacinto G: Hypotension: A major factor limiting recovery from cerebral ischemia. J Surg Res 9:525-529, 1969

44. Garcia JH, Kalimo H, Kamijyo Y, et al: Cellular events during partial cerebral ischemia. Part I: Electron microscopy of feline cerebral cortex after middle-cerebral artery occlusion. Virchows Arch [Cell Pathol] 25:191-206, 1977

45. Kalimo H, Garcia JH, Kamijyo Y, et al: The ultrastructure of "brain death." Virchows Arch [Cell Pathol] 25:207-220, 1977

46. White BC, Winegar CD, Jackson RE, et al: Cerebral cortical perfusion during and following resuscitation from cardiac arrest in dogs. Am J Emerg Med 1:128-138, 1983

47. Gadzinski DS, White BC, Hoehner PJ, et al: Canine cerebral cortical blood flow and vascular resistance post cardiac arrest. Ann Emerg Med 11:58-63, 1982

48. Safar P: Cerebral resuscitation: Current state of the art. Ann Emerg Med 11:162-165, 1982

49. Combs DJ, Reuland DS, Martin DB, et al: Glycolytic inhibition by 2-deoxyglucose reduced hyperglycemia-associated mortality and morbidity in the ischemic rat. Stroke 17:989-994, 1986

50. Kannengiesser GJ, Opie LH, VanDerWerff TJ: Impaired cardiac work and oxygen uptake after reperfusion of regionally ischaemic myocardium. J Mol Cell Cardiol 11:197-207, 1979 